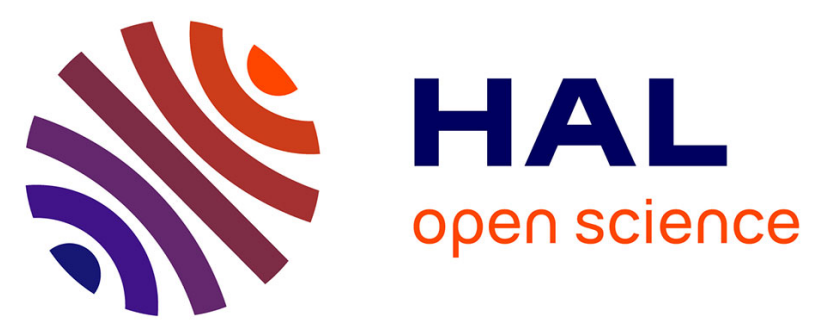

\title{
Temporal estimation of hydrodynamic parameter variability in stormwater constructed wetlands - The hysteresis effect during multi-rainfall events
}

Mohammad Moezzibadi, Isabelle Charpentier, Adrien Wanko, Robert Mosé

\section{- To cite this version:}

Mohammad Moezzibadi, Isabelle Charpentier, Adrien Wanko, Robert Mosé. Temporal estimation of hydrodynamic parameter variability in stormwater constructed wetlands - The hysteresis effect during multi-rainfall events. Ecological Engineering, 2019, 127, pp.1-10. 10.1016/j.ecoleng.2018.11.002 . hal-02322819

\section{HAL Id: hal-02322819 \\ https://hal.science/hal-02322819}

Submitted on 25 Oct 2019

HAL is a multi-disciplinary open access archive for the deposit and dissemination of scientific research documents, whether they are published or not. The documents may come from teaching and research institutions in France or abroad, or from public or private research centers.
L'archive ouverte pluridisciplinaire HAL, est destinée au dépôt et à la diffusion de documents scientifiques de niveau recherche, publiés ou non, émanant des établissements d'enseignement et de recherche français ou étrangers, des laboratoires publics ou privés. 


\title{
Temporal estimation of hydrodynamic parameter variability in stormwater constructed wetlands - The hysteresis effect during multi-rainfall events
}

\author{
Mohammad Moezzibadia, ${ }^{\mathrm{a}, *}$ Isabelle Charpentier ${ }^{\mathrm{a}, \mathrm{b}}$, Adrien Wanko ${ }^{\mathrm{a}, \mathrm{b}}$, Robert Moséa,b \\ ${ }^{a}$ University de Strasbourg, Icube UMR 7357, 2 rue Boussingault, 67000, Strasbourg, France \\ ${ }^{b}$ LTSER France, Zone Atelier Environnementale Urbaine, 3 Rue de l'Argonne, 67000 Strasbourg, France
}

\begin{abstract}
Constructed wetland $(\mathrm{CW})$ systems are increasingly implemented as rustic water treatment facilities, the efficiency of which varies with time due to possible malfunctions such as clogging related to excessive loads of suspended solids or inadequate $\mathrm{CW}$ sizing. A numerical flow modeling can be used to evaluate filtering performance and to improve the design of CWs. Such a modeling usually involves the so-called van Genuchten-Mualem (vGM) soil hydrodynamic parameters which are notoriously difficult to measure. The meticulous attention brought to the sensitivity of the model to the vGM parameters reveals a predominant influence of the shape parameters and the saturated conductivity of the filter on the piezometric heads, during feeding and drainage. We then discuss a simple, robust and low-cost inverse modeling approach, deterministic and stochastic, for the identification of the soil hydrodynamic properties from piezometric heads measured during successive storm events. The temporal variability of hydrodynamic parameters is assessed and analyzed with regards to modeling efficiency. Principal component analysis shows that the estimated hydrodynamic parameters from the feeding and drainage sub-periods are significantly different.
\end{abstract}

Keywords: Stormwater constructed wetland, van Genuchten-Mualem parameters, Sensitivity analysis, Inverse method, Hysteresis effect, Modeling efficiency

2010 MSC: 76S05, 35Q35

\section{Introduction}

Stormwater runoff is a leading threat to surface water quality, due to the large variety of pollutants involved (Zgheib et al. 2012, Schmitt et al. 2015). Urban wet weather discharges are 5 episodic, but recurrent. They may have long term effects on the receiving media and pose serious risks to the quality of ${ }_{30}$ the biotopes. The increase of impervious surfaces puts an even larger pressure on stormwater managers to apply the most efficient practices regarding treatment systems for the removal of 10 both organic and heavy metal pollutants (Daly et al. 2012) for instance, so as to comply with the European Water Framework Directive (Commision Directive, 2008). Thus, many studies have been focused on the impact of urban discharges during rainy episodes and on the best practices for stormwater management. Among these practices, nature-based solutions such as stormwater constructed wetlands (SCWs) are widely studied.

SCWs are engineered systems implemented to manage flood peaks and to reproduce natural treatment processes by means of wetland vegetation, sand and gravel, and their microbial flora, within a monitored environment (Vymazal \& Kropfelova, 2008). They are considered as a sustainable and promising option, whose performance, cost and resources utilization can complement or replace conventional water treatment (Tack

${ }^{*}$ Corresponding author

Email address: moezzibadi@etu.unistra.fr (Mohammad Moezzibadi)

Preprint submitted to Journal of Ecological Engineering et al., 2007; Arias \& Brown, 2009). Stormwater is diverted 25 to the system and, by flowing through the soil media, is subjected to physical and chemical treatment processes such as sedimentation, fine filtration, adsorption and biological uptake (Davis et al. 2009). Their significant efficiency in reducing the ecological impact of urban runoff has been proven in the field (Schmitt et al., 2015). Among SCW systems, planted filters with horizontal or vertical flow have long demonstrated their effectiveness in the treatment of stormwater (Albalawneh et al., 2016). The abilities of SCWs to improve water quality are widely recognized, and their efficiency in reducing suspended solids and micropollutants has been reported in several studies (Tang et al., 2009, Walaszek et al., 2018). Available guidelines and rules for the design of SCW are based on empirical rules of thumb (Brix \& Arias, 2005) derived from experiments under specific conditions. These raise issues about customized design, implementation and operation of SCWs that are necessary to optimize potential treatment efficiency and to limit malfunctions. These may be clogging due to excessive loads of suspended solids, water stress of macrophytes and microorganisms due to extended dry periods, or inadequate SCWs sizing. The predictive ability of simulation tools is of great interest to evaluate the filtering characteristics of a SCW (Langergraber, 2011).

Langergraber (2008) provided a survey of existing simulation tools for SCWs ensuring that measured data from SCWs can be matched. Using the HYDRUS simulation tool when the hydraulic behavior of the system is well described, it was 
concluded that the influence of the hydraulic parameters of the filter material is much higher than that of the biokinetic model parameters. The van Genuchten-Mualem (vGM) model is still one of the most frequently used models for the prediction of hydraulic conductivities. However, the parameters of soil-water retention curves, which are the key functions required in variably saturated porous media involved in environmental and ecological modeling, are difficult to measure. The calibration of hydrodynamic parameters for subsurface SCWs is a sensitive process and remains a challenging task since unsaturated flow modeling involves highly non-linear equations. Several studies investigated how to predict these parameters from basic soil properties. Fournel et al. (2013) used HYDRUS to explore specific features of SCWs. They added a conceptual layer at the bottom of the wetland to mimic the local head loss resulting from seepage boundary condition. Morvannou et al. (2013) also described some characterization of the hydraulic properties of the system by means of direct laboratory methods and 70 inverse modeling from in situ measurements.

An initial set of parameters can be produced by carrying ${ }^{110}$ out a hydrodynamic characterization of porous media. This set can be used in the inverse optimization module included in HYDRUS-1D. Implemented by Morvannou et al. (2013), such

75 a calibration methodology reduces the risk of non-convergence of the model, since the values obtained are likely to be close to ${ }^{115}$ optimal values. As a deterministic inverse approach, a gradient method may be used, but its well-known disadvantage is that it may fall in local minima. Maier et al. (2009) used a global

80 optimization based on a stochastic search strategy in which hydraulic calibration was performed on the outflow rate measure- ${ }^{120}$ ment. Thus, soil hydraulic functions based on vGM coefficients and preferential flow characteristics in large pores at high saturation were obtained. For many actual problems, data cannot be known with certainty due to simple measurement errors.

The variations of soils characteristics, including in particular ${ }^{125}$ the behavior of unsaturated soils, may greatly be influenced by hydrodynamic hystereses, defined as the dependency of capillary pressure saturation curves on the history of the flow. This phenomenon is generally due to several reasons cited by Feddes et al. (1988) such as swelling and shrinkage for fine grained ${ }^{130}$ clays which may result from wetting and drying or thermal effects (Nimmo, 2005). If after one of the two processes the other follows, a sequence of cycles of wetting or drying inner curves, 95 called scanning curves, occurs, which is the case for SCWs receiving randomized stormwater. If the hysteresis phenom- ${ }^{135}$ ena, physically caused by the presence of entrapped air, are not accounted for in the analysis of the behavior of unsaturated soils, this may result in significant errors in the prediction of so-

100 lute movement and contaminant concentrations (Kool \& Parker 1987). Consequently, primary wetting and draining branches of soil-water characteristics have to be considered in calibration process for both empirical (Gillham et al., 1976) and theoretical models (Mualem, 1984). Figure 1 shows a typical example of hysteretic water retention in a soil. The outer drying and wetting curves correspond to the drying from the highest reproducible saturation degree to the residual water saturation and the wetting from the residual water content to the highest satu-

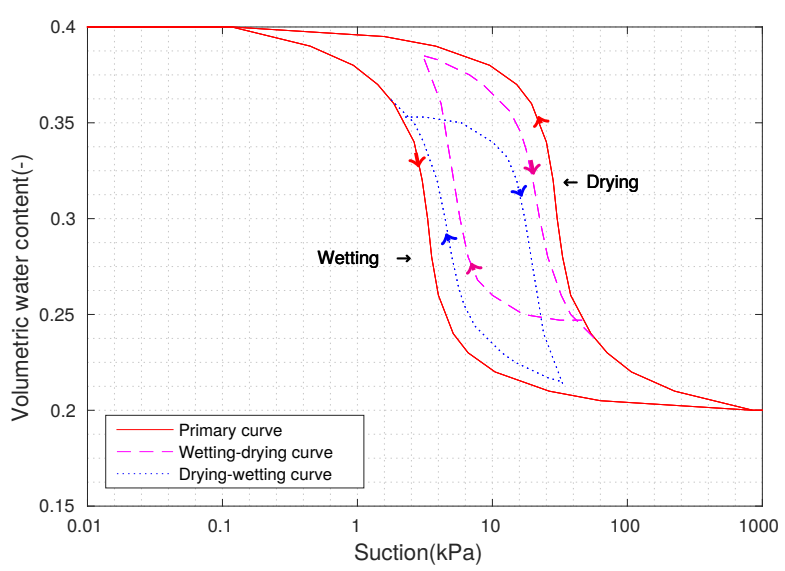

Figure 1: Hysteresis in the moisture characteristic

ration degree, respectively.

The present study focuses on the long-term hydrodynamic characterization by implementing a numerical model of a vertical flow stormwater constructed wetland (VFSCW). The hydrodynamic modelling is carried out by implementing the Richards model by means of a mixed hybrid finite element method (MHFEM) adapted to the simulation of heterogeneous media (Younes et al. 1999), and the van Genuchten-Mualem (vGM) parametrization. Particular attention is given to the top boundary conditions - surface ponding or evaporation - for the purposes of modeling the sequences of rain-runoff events. $\mathrm{MH}-$ FEM results after parameter estimation are compared to those of HYDRUS (Simunek et al., 2009). The monitoring of the VFSCW provides us information in terms of water exchanges, filtering abilities during feeding and drainage sub-periods, and ageing with time. Large datasets are needed to account for significant spatial and temporal variability in the vGM soil parameters hidden behind the hysteresis effect. As such datasets are usually not available, in part due to the randomness of the storm events, the paper presents a simple, robust and low-cost numerical method for the identification of the soil hydrodynamic properties. On the one hand, it relies on the automatic differentiation (AD) of the MHFEM code for sensitivity analysis and gradient-based data assimilation. On the other hand, a stochastic method is implemented to, eventually, determine a global optimum. The modeling efficiency, as defined by Moriasi et al. (2007), and a statistical analysis are then evaluated for the different parameter sets to demonstrate the hysteresis effect.

\section{Methods}

\subsection{Hydrodynamic modeling}

\subsubsection{Governing equations}

For unsaturated flow with an incompressible fluid through porous media, the hydrodynamic equation is obtained by associating the continuity equation with the Buckingham-Darcy's law in which the hydraulic conductivity depends on the pres- 
sure head $h[L]$ and the water content $\theta[-]$ :

$$
\frac{\partial \theta}{\partial t}+S_{s} S_{w}(\theta) \frac{\partial h}{\partial t}+\nabla \cdot \vec{q}=f, \quad \text { in } \quad \Omega,
$$

where $t$ is the time variable [T], $\Omega$ is the flow region here considered as a one dimensional unconfined aquifer, $S_{s}$ and $S_{w}$ are the specific storage $\left[L^{-1}\right]$ and the degree of saturation $[-]$, respec- ${ }_{-155}$ tively. Considering $K$ as the unsaturated hydraulic conductivity $\left[L T^{-1}\right.$ ], the velocity $\vec{q}$ is calculated by the Darcy's law:

$$
\vec{q}=-K(h) \nabla(h+z) .
$$

where the elevation head $z[L]$ is defined positive upward. The hydraulic conductivity through isotropic porous media can be ${ }_{160}$ estimated using:

$$
K=K_{s} K_{r},
$$

where $K_{s}$ is the saturated hydraulic conductivity $\left(L T^{-1}\right)$. The dimensionless relative hydraulic conductivity function $K_{r}$ is given by the modified vGM model (Ippisch et al. 2006):

$$
K_{r}=\left\{\begin{array}{cc}
S_{e}^{\tau}\left[\frac{1-\left(1-\left(S_{e} S_{c}\right)^{1 / m_{v}}\right)^{m_{v}}}{1-\left(1-S c^{1 / m_{v}}\right)^{m_{v}}}\right]^{2}, & \text { for } S_{e}<1, \\
1, & \text { for } S_{e} \geq 1,
\end{array}\right.
$$

where $S_{e}$ is the effective saturation [-] evaluated as:

$$
S_{e}=\left\{\begin{array}{cl}
\frac{1}{S_{c}}\left[1+\left|\alpha_{v} h\right|^{n_{v}}\right]^{-m_{v}}, & h<h_{e}, \\
1, & h \geq h_{e},
\end{array}\right.
$$

and $S_{c}$ is the saturation at the cut-off point $h_{e}$ in the classical vGM model:

$$
S_{c}=\left(1+\left|\alpha_{v} h_{e}\right|^{n_{v}}\right)^{-m_{v}},
$$

where $\alpha_{v}\left[L^{-1}\right], n_{v}[-]$ and $m_{v}[-]$ are the van Genuchten form parameters and $\tau$ [-] is the tortuosity parameter of the matrix. The parameter $h_{e}$ is the air entry value $[L]$.

The dimensionless variable $S_{e}$, referred to as as effective saturation, is defined as a normalized water content (van Genuchten, 1980):

$$
S_{e}=\frac{\theta-\theta_{r}}{\theta_{s}-\theta_{r}}
$$

where $\theta_{r}$ is the residual water content $\left[L^{3} L^{-3}\right]$, defined as the ${ }_{185}$ water content for which the gradient $\frac{d \theta}{d h}$ becomes zero and $\theta_{s}$ is the saturated water content $\left[L^{3} L^{-3}\right]$.

The specific water capacity defined as the slope of the soil moisture characteristic curve at given pressure head $C(h)=\frac{d \theta}{d h}^{190}$ may thus be computed as:

$$
\begin{aligned}
C(h) & =\frac{d\left(S_{e}\left[\theta_{s}-\theta_{r}\right]+\theta_{r}\right)}{d h}, \\
& =\left\{\begin{aligned}
\frac{\alpha_{v} m_{v} n_{v}\left(\theta_{s}-\theta_{r}\right)\left|\alpha_{v} h\right|^{n_{v}-1}}{S_{c}\left(1+\left(\alpha_{v} h\right)^{n_{v}}\right)^{m_{v}+1}}, & \text { for } h<h_{e}, \\
0, & \text { for } h \geq h_{e} .
\end{aligned}\right.
\end{aligned}
$$

As reported in Angelo et al. (2003), the variations of vGM parameters may be significantly influenced by the hysteresis phenomenon between drying and wetting curves (see Fig.
1). As a consequence, soils parameters such as $\alpha_{v}, n_{v}, m_{v}, \theta_{r}$, $\theta_{s}$, and $K_{\text {sat }}$ may vary from the feeding to the drainage subperiods. Moreover the suspended solid and died plant accumulation through the filter along the ageing process may modify the soils' characteristics. Parameter estimation for multirainfall events from observed data is thus important to understand long term hydrodynamic behavior of the SCW.

\subsubsection{Initial and boundary conditions in the SCW numerical domain}

Initial conditions. The initial pressure distribution in the field is set as a hydrostatic distribution which is obtained from the pressure head measured initially by the piezometer in the filter. Thus, the initial piezometric head at the lower and upper parts are approximated.

Top boundary conditions. The drainage occurring after a feeding event can improve the filter bed aeration and the aerobic degradation during the dry period. Modeling issues arise when the soil reaches oven-dry conditions and a special attention should be given to the switching boundary condition procedure, which is important for situations with ponded water layers or fluctuating groundwater near to the soil surface. This procedure swo switches from head (Dirichlet) to flux (Neumann) controlled boundary condition, and vice versa, depending on the saturation of the soil column at the top. The algorithm (Van Dam \& Feddes, 2000, Wanko et al. 2009) is adapted to the mixed hybrid formulation and the $2 \mathrm{D}$ flow problem.

175 Lower boundary conditions. At the bottom of the drainage layer, a "seepage" face boundary condition is chosen. It corresponds to the effectiveness of a flux at the lower boundary when the simulated piezometric head is greater than a threshold limit value.

SCW numerical domain. Fig. 2 displays the conceptual numerical domain, the different layers that have been discretized by triangle elements and boundary conditions. From top to bottom, these layers are composed of $30 \mathrm{~cm}$ of sand layer, 34 $\mathrm{cm}$ of intermediate layer (gravel: $4-8 \mathrm{~mm}$ ) and a drainage layer (gravel and stone: 16-22.4 mm). As previously noted, extended dry periods can have an impact on macrophytes and on microorganisms, leading to a potential decrease in the treatment efficiency. To avoid this, a $16 \mathrm{~cm}$ saturated zone has been laid at the bottom of the filter (Schmitt et al., 2015). Observations of the matrix pressure head at the elevation $-64 \mathrm{~cm}$ are used for the inverse analysis of water flow experiments.

\subsubsection{MHFEM numerical model}

Using the MHFEM, a 2D computational domain is necessary to properly define conditions on the edges of the mesh located at the top and the bottom boundaries of the column. The computational domain $\Omega$ is here discretized using an unstructured mesh containing 160 triangular elements with the same size.

The lumped MHFEM approximation applied to the resolution of the flow in unsaturated heterogeneous porous media 


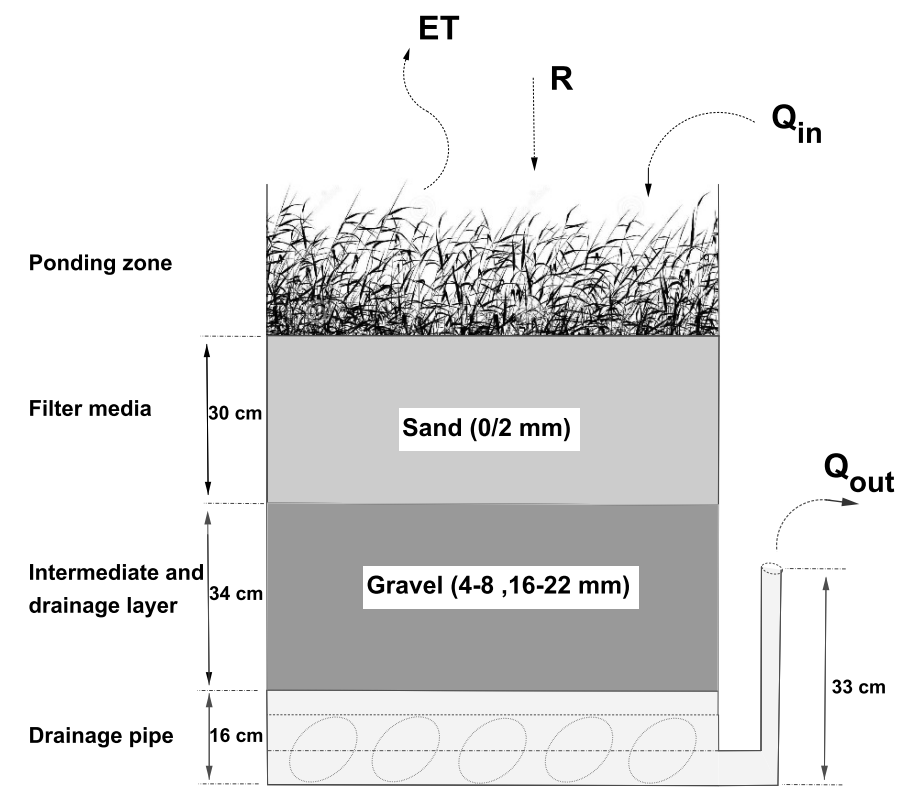

Figure 2: Numerical diagram of the SCW: rain (R), inflow (Qin), evapotranspi- ${ }^{225}$ ration rate (ET) and the outflow from drainage pipe (Qout)

makes it possible to calculate the piezometric head and the velocity on each edge simultaneously (Wanko et al., 2015). Based $_{230}$ on the mixed hybrid formulation presented by Arnold \& Brezzi (1985) and Chavent \& Jaffre (1986), the average piezometric pressure for each edge is chosen as the unknown of the system. It has to be noted that, for each element, the maximum value obtained from the three hydraulic conductivity values at ${ }_{235}$ the edges is considered as the average hydraulic conductivity in that element. This system of equations is solved efficiently by the preconditioned conjugate gradient method.

\subsection{Parameter estimation methodology}

The overall objectives are (1) to identify the vGM parameters with regards to piezometric heads measured in the filter for successive precipitation events and (2) to evaluate model efficiency in its reproduction of the piezometric head data. Calibration with respect to data is a key stage in the numerical modeling of actual events. Some error criteria are described in paragraph 2.2.1, while inverse modelling approaches are described in paragraph 2.2.2.

\subsubsection{Modeling efficiency and statistical analysis}

The agreement between a numerical model and a dataset may be evaluated through error computations.

The classical Mean Square Error (MSE) here measures the difference between piezometric head values $h$ computed by the model and the observed head values $h^{o}$,

$$
\operatorname{MSE}=\frac{1}{n} \sum_{i=1}^{n}\left(h_{i}-h_{i}^{o}\right)^{2} \in(0,+\infty),
$$

at $n$ observation times. MSE is the one of most widely used ${ }_{255}$ criteria for calibration and evaluation of hydrological models with observed data. MSE is positive. It can be expressed in the units of the quantities it compares when a unique variable is considered. However, this absolute "dimensional" criterion has major drawbacks. First, it cannot fairly compare MSEs computed for different variables (heads and velocities, for instance) as units are different. Second, it does not fairly compare MSEs for storm event datasets of different magnitude. Note that a relative dimensionless error such as

$$
\mathrm{rMSE}=\frac{\sum_{i=1}^{n}\left(h_{i}-h_{i}^{o}\right)^{2}}{\sum_{i=1}^{n}\left(h_{i}^{o}\right)^{2}} \in(0,+\infty),
$$

remedies the first drawback only.

The so-called Nash-Sutcliffe efficiency (NSE) is a dimensionless error criterion,

$$
N S E=1-\frac{\sum_{t=1}^{n}\left(h_{i}-h_{i}^{o}\right)^{2}}{\sum_{t=1}^{n}\left(h_{i}^{o}-\mu^{o}\right)^{2}}=1-\frac{M S E}{\left(\sigma^{o}\right)^{2}} \in(-\infty, 1),
$$

that accounts for the mean $\mu^{o}$ and standard deviation $\sigma^{o}$ of the dataset. A value of 1 for NSE indicates a perfect agreement between the model and the dataset. Guidelines were established for model evaluation based on the review of results and projectspecific considerations, see review papers such as Harmel et al. (2006) and Moriasi et al. (2007). Reported NSE values for model calibration and model validation are synthetized in Moriasi et al. (2015).

In this paper, MSE is used for calibration while model efficiency is evaluated from estimated vGM parameters through a NSE computation. Model performance is rated as "very good" if $0.75<\mathrm{NSE}<1.00$, as "good" if $0.65<\mathrm{NSE}<0.75$, as "satisfactory" if $0.50<\mathrm{NSE}<0.65$, and "unsatisfactory" otherwise. Statistical analyses were performed using the open source $\mathrm{R}$ software (R Core Team 2016). A Shapiro-Wilk test was performed on the data set to verify the data were normally distributed (P-value $>0.5$ ). To highlight the hysteresis effect on the parameter estimation, a Principal Component Analysis (PCA) was performed, followed by a hierarchical ascendant classification.

\subsubsection{Inverse modeling}

The general inverse problem defined as

$$
\text { Find } p^{*} \in \mathcal{P} \text { such that } \min _{p \in \mathcal{P}}(\mathcal{J} \circ \mathcal{M}(p))=(\mathcal{J} \circ \mathcal{M})\left(p^{*}\right) \text {, }
$$

is adapted to the paper's objective. The unknown vGM parameters $p$ are searched in the set of admissible values $\mathcal{P}$. The set that minimizes 10 is denoted by $p^{*}$. The objective function $\mathcal{J} \circ \mathcal{M}$ is a compound function that applies MSE to compare simulation results of MHFEM computed by using the parameter set $p$ to piezometric data. Such a minimization problem can be solved using either a gradient method or a stochastic one, depending on the abilities of the software and the availability of its source code.

Prior to that, critical parameters may be determined from a sensitivity analysis in order to downsize the number of unknowns for the inverse problem. From a computer point of view, a sensitivity analysis may be carried out by means of automatic differentiation (AD). In a nutshell, $\mathrm{AD}$ is a set of 


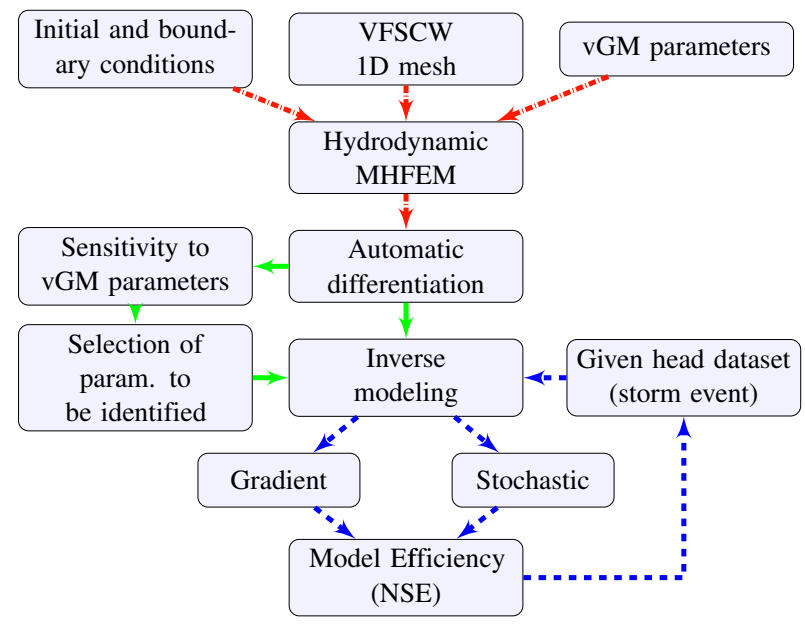

Figure 3: Modeling and temporal identification chart. Top red dash-dotted tree: Modeling hypotheses. Green solid lined subchart: Automatic differentiation and related features. Blue dashed loop: Temporal estimation of hydrodynamic parameter variability.

techniques designed to augment the source code of a software with derivative computations (Griewank \& Walther, 2008, Naumann 2011). It implements the chain rule in either a source $\mathrm{to}_{310}$ source AD tool like Tapenade (Hascoet \& Pascual, 2013) or an AD overloading library (Griewank et al., 1996; Charpentier. 2012) to be linked with the computer code. The AD tool (Hascoet \& Pascual, 2013) is here applied to our MHFEM code. Nowadays, minimal human effort is needed to generate a dif- ${ }_{315}$ ferentiated code (Moezzibadi et al., 2017). Note that it cannot be applied to a black-box software such as HYDRUS.

Under differentiability assumption, a gradient method can be used to find a local minimum satisfying

$$
\text { Find } p^{*} \in \mathcal{P} \text { such that } \nabla(\mathcal{J} \circ \mathcal{M})\left(p^{*}\right)=0 \text {, }
$$

where $\nabla(\mathcal{J} \circ \mathcal{M})$ is the gradient of $\mathcal{J} \circ \mathcal{M}$ calculated with respect to $p$.

270 A basic stochastic method is also implemented in an attempt to find out the global minimum.

\subsubsection{Algorithmic parameter estimation chart}

The proposed parameter estimation methodology is summarized in Fig. 3. The top level red dash-dotted tree is concerned with key modeling hypotheses set on the initial and boundary conditions, the mesh discretization, the soil hydrodynamic pa- -30 rameterization (the vGM model, for instance) and the computer hydraulic model (the proposed MHFEM or HYDRUS, for instance).

280 The green solid lined arrows of the chart are concerned with code differentiation and usages. Automatic differentiation with ${ }_{335}$ respect to vGM parameters is applied to the MHFEM code. The resulting code is used for sensitivity analysis in order to decide on the most sensitive parameters, then for their identification by a gradient method of the vGM parameter values with respect to a given piezometric head dataset.

The blue dashed loop organizes the temporal estimation of vGM parameters along the storm event sequence. It imple- ments a deterministic gradient method as well a stochastic one 290 parameter estimation by evaluating the model efficiency criterion (9).

\subsection{A priori assumptions on $v G M$ modeling parameters}

Practically, in a deterministic calibration, the influence of the initial guess on the final calibrated parameters cannot be neglected. Thus, choosing a suitable initial parameter set ensures that the estimations converge quickly and lead to accurate parameters.

The hydraulic conductivity through isotropic porous media may be approximated using the vGM parameters and the tortuosity parameter of the matrix as described in subsection 2.1.1. A set of seven parameters is used to model a layer of the filter. On the one hand, some of the parameters - residual water content $\left(\theta_{r}\right)$, saturated water content $\left(\theta_{s}\right)$ and saturated hydraulic conductivity $\left(K_{S}\right)$, have a simplified physical meaning. They can be measured in laboratory. Orders of magnitude for $\theta_{r}$ and $\theta_{s}$ are available in the literature for different kind of materials that can be implemented in a VFSCW. Table 1 reports parameter values for the sand layer (Celia et al., 1990) and the fine gravel layer (DanHan-Cheng et al., 2012). It also reports values for the third, virtual, layer (Fournel et al., 2013). On the other hand, the shape parameters $\alpha_{v}$ and $n_{v}$ are generally identified from data (Ippisch et al. 2006). Parameters of Table 1 are used as initial guesses in the identification process.

Assumptions are usually made to reduce the number of modeling parameters to be identified. Following Mualem (1976), the tortuosity parameter of the matrix $\tau$ is set to 0.5 as an average value, while the air entry value $h_{e}$ is set to 0 . As the virtual layer always remains saturated, only the calibration of its saturated conductivity $K_{s}$ and thus the sensitivity of the model with respect to it are required. Finally, the sensitivity analysis results presented in subsection 3.1 allow for downsizing the set of parameters subject to identification and reducing the time intervals dedicated to parameter estimation.

\subsection{Experimental data}

The three-layered VFSCW under study, see Fig. 4, is located in Strasbourg (Alsace, France) at the water edge of the urban water stream Ostwaldergraben. Two aeration pipes are installed between the upper part and the intermediate layer, and at the bottom of the sedimentation pond, to improve the aerobic conditions.

Installed in an exclusively residential zone, the catchment has an area of $18000 \mathrm{~m}^{2}$. Roofs and roads surfaces represent $13.8 \%$ and $15.6 . \%$ of the total area respectively. Datasets of precipitations and piezometric heads were measured during several months (from 16/04/2013 to 18/09/2013). Fig. 5 below shows the characteristics of the rainfall events. Overall, 48 rainfall events were simulated during this work. Remarkably, both the average intensity and the dry period have the highest variabilities (209\% of variation coefficient) and the lowest variability is related to the water depth $(150 \%)$. Regarding the monthly rain characteristics analysis, the dry period during September 
Table 1: Hydraulic properties reported in the literature.

\begin{tabular}{ccccccc}
\hline \multirow{2}{*}{ Layer } & References & $\begin{array}{c}\alpha \\
\left(\mathrm{cm}^{-1}\right)\end{array}$ & $\begin{array}{c}n \\
(-)\end{array}$ & $\begin{array}{c}\theta_{r} \\
(-)\end{array}$ & $\begin{array}{c}\theta_{s} \\
(-)\end{array}$ & $\begin{array}{c}K_{s} \\
\left(\mathrm{~cm}^{2} \mathrm{~min}^{-1}\right)\end{array}$ \\
\hline 1 & Celia et al. (1990) & 0.0335 & 2.0 & 0.102 & 0.368 & 0.5532 \\
2 & DanHan-Cheng et al. (2012) & 1.0 & 2.19 & 0.005 & 0.42 & 2.0 \\
3 & Fournel et al. (2013) & 0.036 & 1.56 & 0.078 & 0.43 & 0.00823 \\
\hline
\end{tabular}

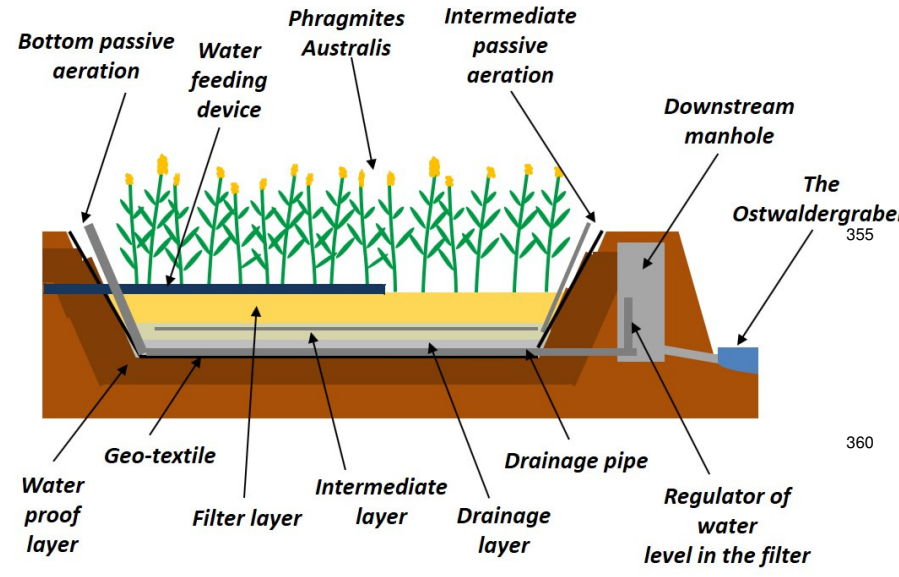

Figure 4: Schematic diagram of a vertical flow filter (cross-section view)

presents the highest variability (275\% of variation coefficient). The variability of the return periods of the events accentuates ${ }_{370}$ the hysteresis phenomenon (see Fig. 5) since the saturation condition of the porous media can be different before each rainfall event (see Fig. 1). The ability of the model to simulate a wide range of event $\mathrm{s}$ is then assessed. Readers seeking more detail about the SCW instrumentation are referred to Walaszek ${ }_{375}$

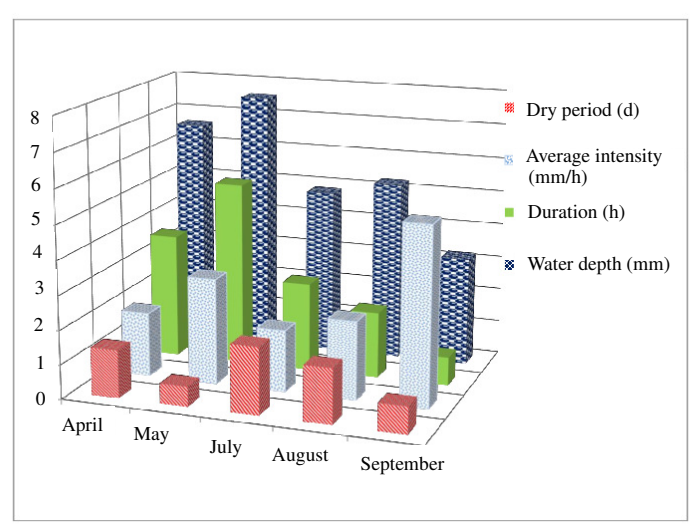

Figure 5: Characteristics of simulated rainfall events.

\section{Results and discussion}

\subsection{Sensitivity analysis and temporal parameter estimation}

The sensitivities of our MHFEM model to various vGM parameters of the first layer and the saturated hydraulic conductivity of the last layer were examined. To that end, a perturbation of $50 \%$ was applied to the vGM parameters related to the first layer and to the hydraulic conductivity of the third layer.

Figure 6-a represents the sensitivity of water pressure to vGM parameters for the 1st period of May. The parameters identified as having the greatest influence are: the saturated water content $\theta^{\text {sat }}$ and the form parameter $\alpha$ for the first layer, the hydraulic conductivity $K^{\text {sat }}$ for the last layer. The parameters $n$, $K^{s a t}$ and $\theta^{r e s}$ for the filter layer can modify the water pressure profile, particularly during each rainfall event, thus their influpresented as a zoom and simplified plot of a rainfall event. The temporal intervals in which each parameter can be estimated are highlighted with different patterns. The major influence of the hydraulic conductivity of the virtual layer is revealed by its higher sensitivity compared to those of the first layer. This corresponds, physically, to the role of the drainage pipe. Very small sensitivity results (the sensitivity of water pressure with respect to the hydraulic conductivity of the intermediate layer is zero, for instance), are not presented here.

Considering that (1) the sensitivity analysis which highlights the most influential parameter (specifically the hydraulic conductivity for the virtual layer), and (2) the variations of properties due to plant activity (decay, growth and death) and suspended solid accumulation are expected for the first layer only, throughout the calibration process.

\subsection{Parameter estimation and model efficiency}

Calibration of the sensitive parameters is carried out through inverse modeling by implementing both a deterministic method (gradient) and a stochastic method (simple random processing) and by using the data collected during 48 rainfall events. The temporal estimation of the considered parameters and the efficiency of the two methods are then discussed.

\subsubsection{Parameter estimation for multi-rainfall events}

Values of vGM parameters and related MSE and NSE estimated using the gradient method onto the MHFEM code are reported in Table 2. At a first glance, unsatisfactory NSEs show that the model run from estimated parameters partially fails to reproduce the measured piezometer. In particular, the use of 


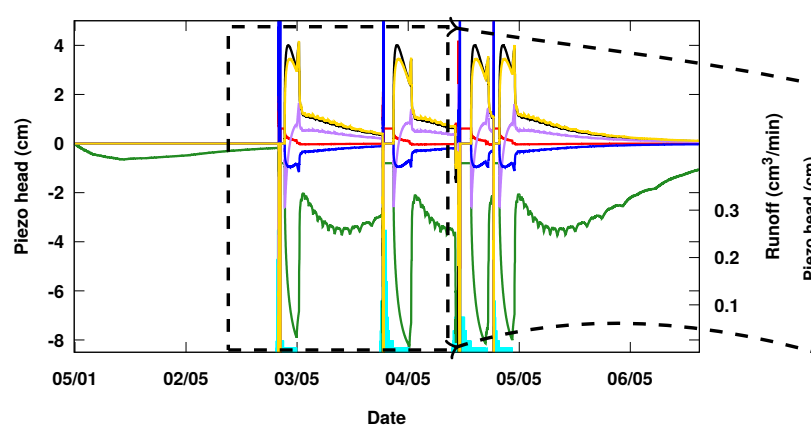

(a)

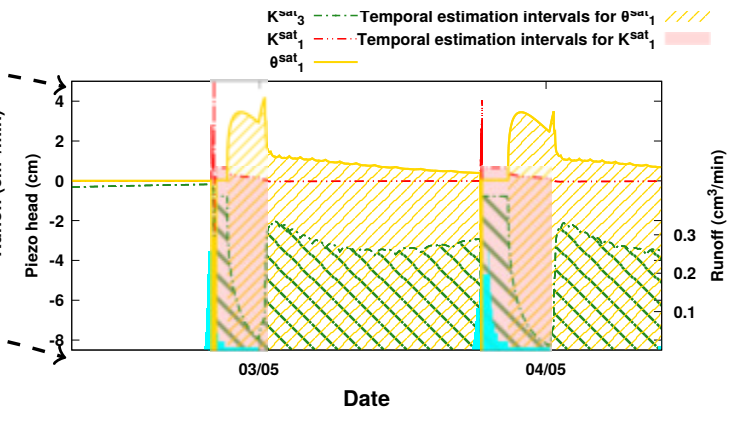

(b)

Figure 6: Sensitivity of water pressure to vGM parameters time-series. (a) Sensitivities during 1st period of May (b) Calibration strategy and temporal estimation intervals.

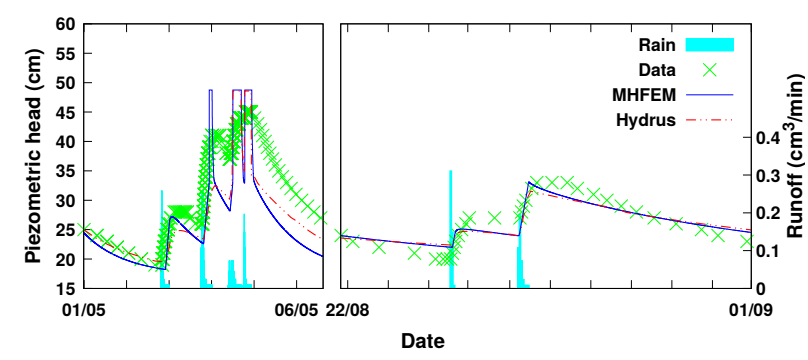

(a)

Figure 7: Piezometric heads computed from estimated parameters for multirainfall events: (a) Unsatisfactory calibration $(\mathrm{NSE}=0.410)$ (b) Very good cali- ${ }^{4}$ bration $(\mathrm{NSE}=0.878)$

in unsatisfactory NSE values. Looking at the rain characteristics during these periods, one can see that the highest average ${ }_{425}$ rain event intensity occurred in September followed by May, while the highest water depth occurred in May (see Fig. 5). Hence the average rain event intensity may have a significant impact on the quality of the parameter estimation.

The calibration for the multi-rainfall event periods is per-430 formed using the gradient method. Fig. 7fa illustrates that some of the identified parameter sets are unable to properly simulate the water head observed in the VFSCW and the results are not dominantly in accordance with observed data. Meanwhile, Fig. 77b displays very well-fitted piezometric head data $a_{435}$ series during August. One notices that HYDRUS-1D and MHFEM yield the same global trend: the two models failed to fit the drainage sub-periods. The NSE values evaluated for multirainfall event periods (see Table 2 make it clear that ignoring the hysteresis effect may be one of the causes of these mis- 440 matches. Thus, two other extra groups of calibrations depending on the precipitation occurrence are provided during feeding sub-periods and drainage sub-periods.

\subsubsection{Parameter estimation during feeding sub-periods} 445

In the paper, feeding periods are defined as temporal ranges corresponding to piezometric head data series with increasing

Table 2: Multi-rainfall events. Optimized parameters (gradient method) and NSE: very good (green), good (blue), satisfactory (orange), unsatisfactory (red).

\begin{tabular}{lllllllrr}
\hline Month & $\begin{array}{l}\alpha_{1} \\
\left(\mathrm{~cm}^{-1}\right)\end{array}$ & $\begin{array}{l}n_{1} \\
(-)\end{array}$ & $\begin{array}{l}\theta_{r 1} \\
(-)\end{array}$ & $\begin{array}{l}\theta_{s 1} \\
(-)\end{array}$ & $\begin{array}{l}K_{1} \\
\left(\mathrm{~cm} . \mathrm{min}^{-1}\right)\end{array}$ & $\begin{array}{r}M S E \\
\left(\mathrm{~cm}^{2}\right)\end{array}$ & $\begin{array}{r}\text { NSE } \\
(-)\end{array}$ \\
\hline 04 & .981 & 2.52 & .006 & .17 & .023 & .0026 & 32.49 & .862 \\
$05(1)$ & .081 & 2.13 & .057 & .12 & .016 & .0041 & 38.96 & .410 \\
$05(2)$ & .082 & 4.22 & .061 & .33 & .017 & .0011 & 82.59 & -.250 \\
07 & .957 & 2.55 & .002 & .17 & .022 & .0025 & 3.01 & .968 \\
08 & .003 & 1.89 & .022 & .19 & .007 & .0005 & 2.11 & .878 \\
09 & .043 & 2.95 & .023 & .40 & .008 & .0016 & 25.66 & .433 \\
\hline
\end{tabular}

value. Some examples are provided in Fig. 8 which plots observed and piezometric heads computed from estimated parameters reported in Table 3. Among the eleven simulated feeding sub-periods, six optimized sets of parameters provide good to very good NSEs. One observes in Fig. 8 that the model predicts drainage sub-periods, mostly when runoff stops. This disagreement is monitored by NSE computations, see Table 3 . This indicates that the calibration process - modeling, inverse modeling and gradient method - often fails at identifying the parameters. A well-known issue is that a gradient method can be trapped in a local minimum. However, the stochastic inverse method involving 1000 parameter sets did not fare better, for any of these events. In the present case, the failure explanation is mainly within the modeling hypotheses for ponding and infiltration, which depend on the saturation of the soil on the top of the filter. Other assumptions can also interfere. For instance, the three-dimensional behavior of the water flow may be predominant during the feeding process since surface flow may occur near to the top layer.

Obviously, no trend on the evolution of the parameter value can be deduced from Table 3 since some of the NSE values are less than 0.5. Crossing the NSE values from Table 3 with the rain event characteristics, the lowest NSE values are obtained only during May. These events are remarkably identified by the highest average water depth and the highest average intensity (see Fig. 5). Comparing the results of Table 3 with those obtained after the multi-rainfall events parameter estimation (see Table 2, meanwhile, there is an improvement of the calibration highlighted by a global increase of the NSE values. 


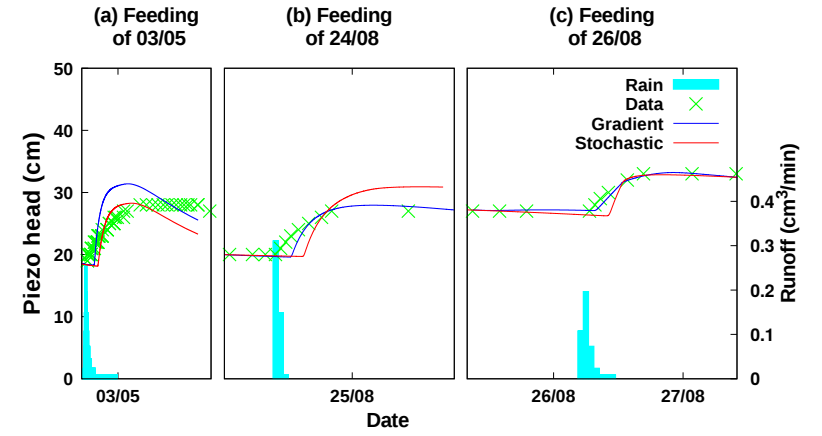

Figure 8: Observed and computed piezometric heads for three feeding periods: (a) $\mathrm{NSE}=0.35$, (b) $\mathrm{NSE}=0.84$, (c) $\mathrm{NSE}=0.99$.

Table 3: Feeding periods. Optimized parameters (gradient method) and NSE.

\begin{tabular}{rllllllrr}
\hline $\begin{array}{r}\text { Start } \\
\text { date }\end{array}$ & $\begin{array}{l}\alpha_{1} \\
\left(\mathrm{~cm}^{-1}\right)\end{array}$ & $\begin{array}{l}n_{1} \\
(-)\end{array}$ & $\begin{array}{l}\theta_{r 1} \\
(-)\end{array}$ & $\begin{array}{l}\theta_{s 1} \\
(-)\end{array}$ & $\begin{array}{l}K_{1} \\
\left(\mathrm{~cm} \mathrm{~min}^{-1}\right)\end{array}$ & $\begin{array}{r}K_{3} E \\
\left(\mathrm{~cm}^{2}\right)\end{array}$ & $\begin{array}{r}\text { NSE } \\
(-)\end{array}$ \\
\hline $16 / 04$ & .010 & 2.31 & .013 & .05 & .009 & .0008 & .48 & .97 \\
$25 / 04$ & .924 & 2.77 & .007 & .15 & .028 & .0034 & 33.86 & .84 \\
$02 / 05$ & .151 & 2.63 & .110 & .48 & .346 & .0087 & 11.55 & -.35 \\
$03 / 05$ & .877 & 4.94 & .013 & .81 & .420 & .0116 & 15.49 & .35 \\
$04 / 05$ & .889 & 4.95 & .028 & .71 & .422 & .0071 & 8.72 & -.03 \\
$26 / 05$ & .137 & 2.02 & .005 & .35 & .028 & .0038 & 27.72 & .58 \\
$29 / 05$ & .026 & 1.73 & .013 & .90 & .026 & .0100 & 32.03 & .34 \\
$02 / 07$ & .387 & 3.04 & .092 & .44 & .027 & .0005 & .77 & .98 \\
$24 / 08$ & .062 & 8.14 & .012 & .24 & .019 & .0011 & 1.50 & .84 \\
$26 / 08$ & .045 & 8.49 & .016 & .23 & .005 & .0008 & .03 & .99 \\
$08 / 09$ & .035 & 3.81 & .029 & .29 & .010 & .0021 & 12.78 & .72 \\
\hline
\end{tabular}

\subsubsection{Parameter estimation during drainage sub-periods}

Here, drainage sub-periods are defined as temporal ranges corresponding to piezometric head data series with decreasing value. Modeling parameters identified for a total of ten different drainage sub-periods are reported in Tables 4 and 5 Some examples are provided in Fig. 9, which plots observed and piezometric heads computed from estimated parameters reported in Table 4 and 5 Their variations with time can be better observed in Fig. 10 for the gradient method (blue $\nabla$ ) and the stochastic method (red $\mathbf{\nabla})$.

Hydraulic conductivities. In Fig. 10f, the curves related to virtual layer hydraulic conductivity $\left(K_{3}\right)$ at the bottom of the filter display similar trends for both gradient and stochastic methods. From April to September, $K_{3}$ decreases, suggesting that the flowing capacity of water through the virtual layer diminishes with time. This phenomenon might be due to the migration of fine particles, suspended solid or root debris from the

465 top layer to the bottom, which houses the drainage pipe. The trend of the top layer hydraulic conductivity $\left(K_{1}\right)$ is completely different to the third layer one (see Fig. 10 -e). There is no evidence of a reduction in the infiltration capacity of the top layer which is likely to accumulate particles as well as the root system. In fact some phenomena with opposite impact on the top layer hydraulic conductivity might occurred over the months. The filtration process on the top layer might reduce the infiltration capacity but stalling due to shear stresses during water flow
Table 4: Drainage sub-periods. Optimized parameters (gradient method) and NSE.

\begin{tabular}{rlllllllr}
\hline $\begin{array}{r}\text { Start } \\
\text { date }\end{array}$ & $\begin{array}{l}\alpha_{1} \\
\left(\mathrm{~cm}^{-1}\right)\end{array}$ & $\begin{array}{l}n_{1} \\
(-)\end{array}$ & $\begin{array}{l}\theta_{r 1} \\
(-)\end{array}$ & $\begin{array}{l}\theta_{s 1} \\
(-)\end{array}$ & $\begin{array}{c}K_{1} \\
\left(\mathrm{~cm} . \mathrm{min}^{-1}\right)\end{array}$ & $\begin{array}{r}K_{3} \\
\left(\mathrm{~cm}^{2}\right)\end{array}$ & $\begin{array}{r}\text { NSE } \\
(-)\end{array}$ \\
\hline $17 / 04$ & .005 & 1.68 & .250 & .30 & 0.557 & .0044 & 3.642 & .836 \\
$28 / 04$ & .500 & 2.80 & .190 & .48 & 0.148 & .0025 & 0.119 & 998 \\
$01 / 05$ & .011 & 2.00 & .080 & .39 & 0.550 & .0027 & 0.198 & .934 \\
$05 / 05$ & .412 & 2.89 & .024 & .64 & 0.347 & .0038 & 0.293 & .990 \\
$27 / 05$ & .590 & 3.85 & .068 & .65 & 0.250 & .0028 & 0.497 & .981 \\
$30 / 05$ & .067 & 1.48 & .010 & .74 & 0.832 & .0008 & 0.063 & .993 \\
$03 / 07$ & .498 & 5.10 & .010 & .95 & 1.106 & .0024 & 0.458 & .996 \\
$21 / 08$ & .034 & 2.00 & .102 & .37 & 0.553 & .0014 & 0.028 & .989 \\
$26 / 08$ & .053 & 2.23 & .089 & .41 & 0.550 & .0011 & 0.010 & .999 \\
$01 / 09$ & .003 & 2.03 & .020 & .23 & 0.550 & .0014 & 0.280 & .945 \\
\hline Mean & .217 & 2.61 & .102 & .52 & 0.544 & .0023 & & \\
Dev. & .248 & 1.12 & .084 & .22 & 0.275 & .0012 & & \\
Min & .003 & 1.48 & .010 & .23 & 0.148 & .0008 & & \\
Max & .590 & 5.10 & .250 & .95 & 1.106 & .0044 & & \\
\hline
\end{tabular}

Table 5: Drainage sub-periods. Optimized parameters (stochastic method) and NSE.

\begin{tabular}{rllllllllr}
\hline $\begin{array}{r}\text { Start } \\
\text { date }\end{array}$ & $\begin{array}{l}\alpha_{1} \\
\left(\mathrm{~cm}^{-1}\right)\end{array}$ & $\begin{array}{l}n_{1} \\
(-)\end{array}$ & $\begin{array}{l}\theta_{r 1} \\
(-)\end{array}$ & $\begin{array}{l}\theta_{s 1} \\
(-)\end{array}$ & $\begin{array}{c}K_{1} \\
\left(\mathrm{~cm} . \mathrm{min}^{-1}\right)\end{array}$ & $\begin{array}{r}K_{3} \\
\left(\mathrm{~cm}^{2}\right)\end{array}$ & $\begin{array}{r}\text { NSE } \\
(-)\end{array}$ \\
\hline $17 / 04$ & .005 & 1.01 & .453 & .76 & 0.648 & .0038 & 3.897 & .825 \\
$28 / 04$ & .416 & 2.40 & .160 & .58 & 0.223 & .0035 & 0.308 & .996 \\
$01 / 05$ & .052 & 1.61 & .144 & .27 & 1.080 & .0033 & 0.235 & .921 \\
$05 / 05$ & .446 & 2.59 & .182 & .69 & 0.893 & .0034 & 0.253 & .992 \\
$27 / 05$ & .110 & 5.21 & .168 & .93 & 0.814 & .0029 & 1.177 & .954 \\
$30 / 05$ & .061 & 2.82 & .016 & .70 & 0.678 & .0012 & 0.203 & .978 \\
$03 / 07$ & .402 & 4.09 & .079 & .92 & 0.206 & .0021 & 1.054 & .990 \\
$21 / 08$ & .049 & 5.17 & .080 & .68 & 0.139 & .0014 & 0.025 & .990 \\
$26 / 08$ & .060 & 3.07 & .082 & .39 & 0.550 & .0011 & 0.016 & .998 \\
$01 / 09$ & .004 & 2.28 & .173 & .40 & 0.970 & .0014 & 0.288 & .943 \\
\hline Mean & .161 & 3.03 & .154 & .63 & 0.620 & .0024 & & \\
Dev. & .183 & 1.40 & .118 & .22 & 0.336 & .0010 & & \\
Min & .004 & 1.01 & .016 & .27 & 0.139 & .0011 & & \\
Max & .446 & 5.21 & .453 & .93 & 1.080 & .0038 & & \\
\hline
\end{tabular}

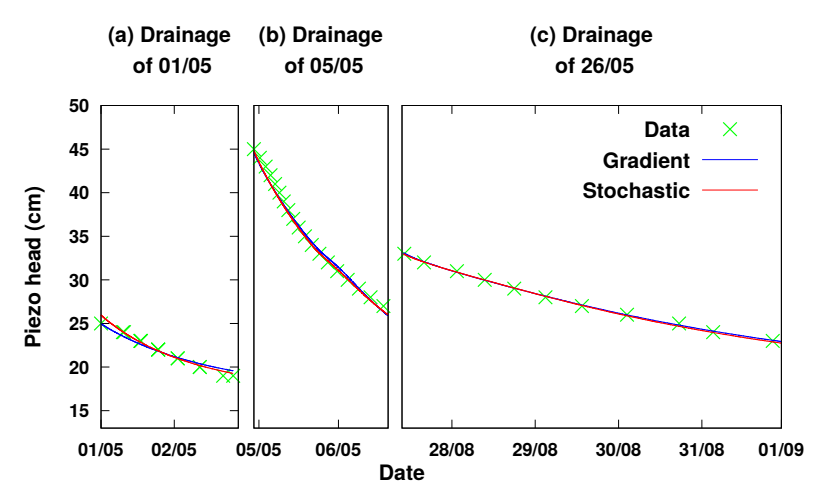

Figure 9: Observed and computed piezometric heads for drainage periods : (a) $\mathrm{NSE}=0.921$, (b) NSE=0.992, (c) $\mathrm{NSE}=0.998$. 
(a) Variations of $\alpha_{1}$ along the sequence of drainage sub-periods

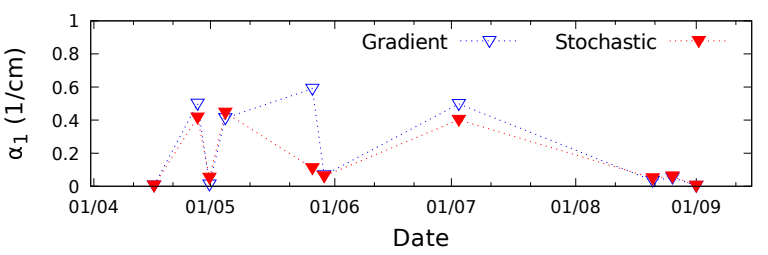

(b) Variations of $n_{1}$ along the sequence of drainage sub-periods

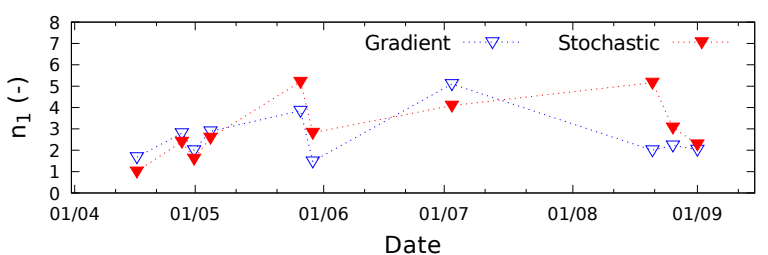

(c) Variations of $\theta_{\mathrm{r} 1}$ along the sequence of drainage sub-periods

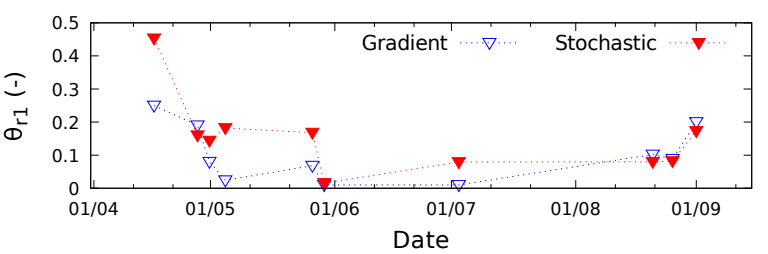

(d) Variations of $\theta_{\mathrm{s} 1}$ along the sequence of drainage sub-periods

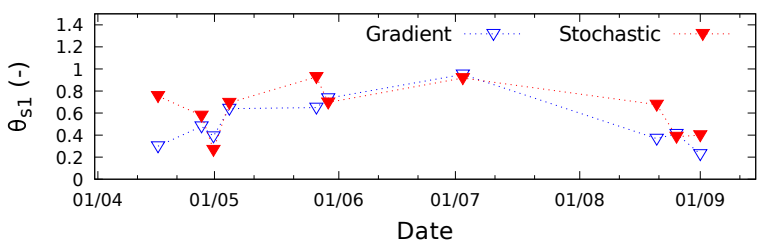

(e) Variations of $K_{1}$ along the sequence of drainage sub-periods

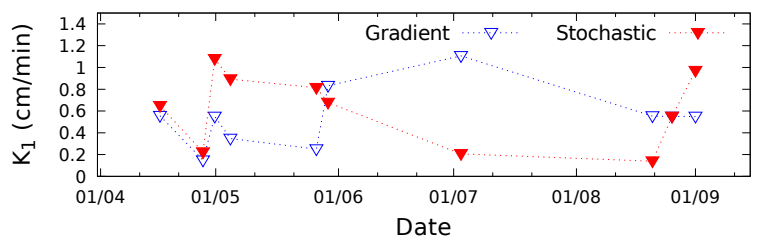

(f) Variations of $K_{3}$ along the sequence of drainage sub-periods

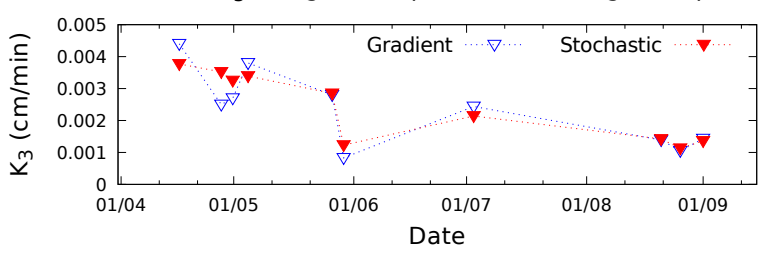

Figure 10: Temporal variability of vGM parameters along the drainage subperiods: (a) $\alpha_{1}$; (b) $n_{1}$; (c) $\theta_{r 1}$; (d) $\theta_{s 1}$; (e) $K_{1}$; (f) $K_{3}$. through porous media for high rain event intensity as well as the seasonal dynamic of vegetation could increase the permeability.

Water content. Residual and saturated water content displayed opposite trends (see Figs. 10-c and 10-d). Process dynamics previously highlighted inside the planted porous media could explain this result. While the residual water content is closely associated with the capillary forces due to accumulated fine particles and the roots dynamic, the saturated water content could be impacted by porous media reorganization due to plant growth, settlement or swelling of sand or gravel layers.

$v G M$ form parameters. Even if gradient and stochastic methods provide similar trends for top layer $\alpha$ and $n$ parameters, there is no clear explanation. Physically, the drainage process occurs through a vertical flow in porous media when gravitational forces are higher than capillary ones. Hence the porous media changed from near saturated condition characterized by the lack of form parameters in $K_{r}$, see (4), toward unsaturated one that is sensitive to the form parameters. Furthermore, the parameter $\alpha$ provides the highest variability of estimated parameters regardless the numerical method (see Tables 4 and 5). Hence it will be clearly difficult to catch the meaning of this parameter over multi-rainfall events.

Several conclusions arise. First, model efficiencies (NSE) are evaluated as very good for all these drainage events, whatever the inverse method. Second, parameters identified by one or the other inverse method are generally close, but some differences may exist even for NSEs above 0.95. This assesses the temporal variability of top layer vGM parameters from one drainage period to another.

\subsubsection{Hysteresis effect on parameter estimation}

Results discussed in the previous paragraphs highlighted the the MHFEM model partly failed to properly estimate the vGM parameters for hydrodynamic characterization through vertical flow stormwater constructed wetland when considering the multi-rainfall events. After dividing the water flow process with feeding and drainage sub-periods, better parameters are discussed in order to understand the hysteresis effect.

For very good parameter identifications (NSE > 0.75), a PCA for the optimized vGM parameters is provided in Fig. 11. The variables are the estimated parameters. The first principal component axis $(33,3 \%)$ is negatively well-correlated with the saturated hydraulic conductivity of the first and third layers. The second principal component axis $(26.1 \%)$ is in a negative correthe larger the residual water content value, the smaller the $\alpha$ and $n$ values. Sand material has clearly small $n$ and $\alpha$ values, knowing that the $\alpha$ value is related to the inverse of the air entry pressure value and the $n$ value depends on the width of the ones are significantly separated (see Fig. 11): the PCA highlights that the estimated parameters of the feeding sub-periods 


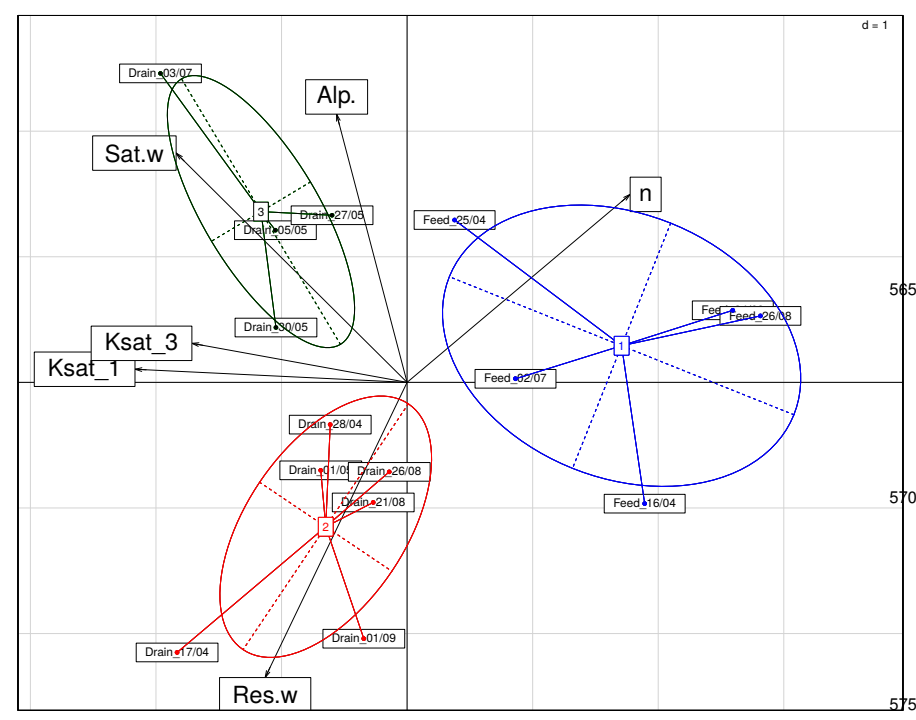

Figure 11: Biplot of individuals and variables - Principal Component Analysis for variables: Alp. and n: vGM form parameters. Ksat_1: Saturation hydraulic conductivity for the first layer. Ksat_3: Saturation hydraulic conductivity for the third layer. Res.w: Residual water content. Sat_w: Saturated water content for individuals: Feed_x/y and Drain_x/y represent respectively the feeding and drainage sub-period occuring ate the start date day/month.

are clearly different from those of the drainage sub-periods due to hysteresis effect. The NSE values without considering feeding and drainage sub-periods would be reduced enormously.

In addition, the Shapiro-Wilk test proves that among all the estimated parameters, the saturated hydraulic conductivity of the first layer $(w=0.8837, \mathrm{p}$-value $=0.05384)$, the saturated hydraulic conductivity of the third layer $(w=0.9077,585$ $\mathrm{p}$-value $=0.1249)$ and the saturated water content $(w=0.9588$, $\mathrm{p}$-value $=0.6720$ ) are normally distributed. The homogeneity of variances are verified by the Levene's test. Thus, the analysis of variance explains the influence of the feeding and drainage subperiods on $(i)$ the estimated value of the saturated water content is significant $(\operatorname{Pr}(>F)=0.0095)$; $($ ii $)$ the first layer saturated 590 hydraulic conductivity is considerable $(\operatorname{Pr}(>F)=0.0010)$; (iii) the last layer saturated conductivity is not significant because the outlet boundary condition governs the hydrodynamic process in the third layer.

Moreover, a successful temporal estimation of parameters during feeding and drainage sub-periods can bring useful information about long term SCW hydrodynamic variations. Fig. 1 -s in the supplementary material highlights the temporal vari-600 ations of vGM parameters during these feeding (blue $\boldsymbol{\Delta}$ ) and drainage (blue $\nabla$ ) sub-periods.

\section{Conclusions}

This study discusses numerical approaches to investigate the temporal variability of $\mathrm{vGM}$ parameters in a VFSCW during multi-rainfall periods considering the hysteresis effect. The re- ${ }^{610}$ sults show that the characteristics of the filter layer alter with time. This indicates that several issues such as water accumulation due to biomass and plants growth, presence of organic matter, and the relying of total suspended solids in this layer have ${ }^{615}$ to be considered or discussed within the modeling. The pres- parameter sets are not perfectly in accordance with observed data as revealed by the NSE evaluations for some periods. In particular, those with the high average rain event intensity were not ranked as satisfactory. Thus, the study had to focus on the impact of the hysteresis effect on the calibration process.

The calibrated parameters during both drainage and feeding sub-periods, which are provided by gradient and stochastic optimizations, demonstrate the same temporal variations. However, a few discordances between the parameters identified by the two implemented methods may be strongly due to either the risk of trapping in local minima using a gradient method or an insufficient number of random parameters processed by the stochastic calibration. Furthermore, several optimizations during feeding sub-periods are unsatisfactory, implying that $\mathrm{MH}-$ FEM as well as HYDRUS cannot be able to properly reproduce the observed wetting periods. In addition, errors in observed data may also produce these mismatches. The statistical analysis carried out on the different parameter sets showed that the estimated parameters of the feeding sub-periods are clearly different from those of the drainage sub-periods, which evidences the hysteresis effect.

\section{Acknowledgements}

Mohammad Moezzibadi was supported by the YEKAN Center Grant No. 139392351345000041.

\section{References}

\section{References}

Albalawneh, A., Chang, T., Chou, C., \& Naoum, S. (2016). Efficiency of a horizontal sub-surface flow constructed wetland treatment system in an arid area. Water, 8 .

Angelo, A., Guido, C., \& Antonio, C. (2003). Hysteresis in soil water characteristics as a key to interpreting comparisons of laboratory and field measured hydraulic properties. Water Resources Research, 39. URL: https://agupubs.onlinelibrary.wiley.com/ doi/abs/10.1029/2003WR002432 doi 10.1029/2003WR002432 arXiv:https://agupubs.onlinelibrary.wiley.com/doi/pdf/10.1029/2003

Arias, M., \& Brown, M. (2009). Feasibility of using constructed treatment wetlands for municipal wastewater treatment in the bogota savannah, colombia. Ecological Engineering, 35, 1070 - 1078. URL: http://www . sciencedirect.com/science/article/pii/S0925857409000871 doi http://dx.doi.org/10.1016/j.ecoleng.2009.03.017

Arnold, D., \& Brezzi, F. (1985). Mixed and non conforming finite element methods: Implementation,postprocessing and error estimates. Mathematical 1. modelling and numerical analysis, 19, 7 - 32. URL: http://www-users. math.umn.edu/ arnold/papers/minc.pdf

605 Brix, H., \& Arias, C. A. (2005). The use of vertical flow constructed wetlands for on-site treatment of domestic wastewater: New danish guidelines. Ecological Engineering, 25, 491 - 500. URL: http://www . sciencedirect.

com/science/article/pii/S0925857405001576 doi/https://doi. org/10.1016/j.ecoleng.2005.07.009 Constructed wetlands for wastewater treatment.

Celia, M., Bouloutas, E., \& Zarba, R. (1990). A general mass-conservative numerical solution for the unsaturated flow equation. Water Re-

sources Research, 26, 1483-1496. URL: http://dx.doi.org/10.1029/ WR026i007p01483 doi 10.1029/WR026i007p01483

Charpentier, I. (2012). On higher-order differentiation in nonlinear mechanics. Optim. Method. Softw., 27, 221-232.

Chavent, G., \& Jaffre, J. (1986). Mathematical models and finite elements for reservoir simulation. North Holland:Amesterdam, 61, 367. 
Commision Directive, E. (2008). Directive 2008/105/EC of the European par-690 liament and of the council of 16 on environmental quality standards in the field of water policy. Official Journal of the European Union. URL: http:

//eur-lex.europa.eu/legal-content/EN/TXT/?uri=uriserv: OJ.L_.2008.158.01.0017.01.ENG\&toc=0J :L:2008:158:TOC

Daly, E., Deletic, A., Hatt, B. E., \& Fletcher, T. D. (2012). Modelling of 695 stormwater biofilters under random hydrologic variability: a case study of a car park at monash university, victoria (australia). Hydrological Processes, 26, 3416-3424. URL: http://dx.doi.org/10.1002/hyp.8397 doi $10.1002 /$ hyp. 8397

DanHan-Cheng, XinPei, LiLing, LiLiang, \& LockingtonDavid (2012).700 Capillary effect on flow in the drainage layer of highway pavement. Canadian Journal of Civil Engineering, 39, 654-666. URL: https://doi.org/10.1139/12012-050 doi 10.1139/12012-050 arXiv:https://doi.org/10.1139/12012-050

Davis, A., Hunt, W., Traver, R., \& Clar, M. (2009). Bioretention technology:705 Overview of current practice and future needs. Journal of Environmental En-

gineering, 135, 109-117. doi 10.1061/(ASCE) 0733-9372(2009)135: 3(109)

Feddes, R., Kabat, P., Bakel, P. V., Bronswijk, J., \& Halbertsma, J. (1988). Modelling soil water dynamics in the unsaturated zone - state 710

640 of the art. Journal of Hydrology, 100, $69-111$. URL: http://www . sciencedirect.com/science/article/pii/0022169488901825 doi https ://doi.org/10.1016/0022-1694(88)90182-5

Fournel, J., Forquet, N., Molle, P., \& Grasmick, A. (2013). Modeling constructed wetlands with variably saturated vertical subsurface-715 flow for urban stormwater treatment. Ecological Engineering, 55, 1 -8. URL:http://www.sciencedirect.com/science/article/pii/ S0925857413000736 doi http://dx.doi.org/10.1016/j.ecoleng. 2013.02.004

van Genuchten, M. (1980). A closed-form equation for predicting the hydraulic720 conductivity of unsaturated soils. Soil Science Society of America Journal, 44(5), 892-898

Gillham, R., Klute, A., \& Heermann, D. (1976). Hydraulic properties of a porous medium: Measurement and empirical representation 1. Soil Science Society of America Journal, 40, 203-207.

655 Griewank, A., Juedes, D., \& Utke, J. (1996). Algorithm 755: Adol-c: A package for the automatic differentiation of algorithms written in $\mathrm{c} / \mathrm{c}++. A C M$ Trans. Math. Softw., 22, 131-167.

Griewank, A., \& Walther, A. (2008). Evaluating Derivatives. (2nd ed.). Society for Industrial and Applied Math-730 ematics. URL: http://epubs.siam.org/doi/abs/10. 1137/1.9780898717761 doi $10.1137 / 1.9780898717761$ arXiv:http://epubs.siam.org/doi/pdf/10.1137/1.9780898717761

Harmel, D., Cooper, J., Slade, M., Haney, L., \& Arnold, G. (2006). Cumulative uncertainty in measured streamflow and water quality data for small wa-735 tersheds. Transactions of the ASABE, 49, 689. URL: http://elibrary. asabe. org/abstract . asp?aid=20488\&t $=3$

Hascoet, L., \& Pascual, V. (2013). The tapenade automatic differentiation tool: Principles, model, and specification. ACM Trans. Math. Softw., 39, 20:1-20:43. URL: http://doi.acm.org/10.1145/2450153.2450158 740 doi 10.1145/2450153.2450158

Ippisch, O., Vogel, H., \& Bastian, P. (2006). Validity limits for the van Genuchten-Mualem model and implications for parameter estimation and numerical simulation. Advances in Water Resources, 29, 1780 - 1789. URL: http://www.sciencedirect. 675 com/science/article/pii/S0309170805003015 doi/http: //dx.doi.org/10.1016/j.advwatres.2005.12.011

Kool, J., \& Parker, J. (1987). Development and evaluation of closed-form expressions for hysteretic soil hydraulic properties. Water Resources Research, 23, 105-114. URL:750

680 https://agupubs.onlinelibrary.wiley.com/doi/abs/ 10.1029/WR023i001p00105 doi 10.1029/WR023i001p00105 arXiv:https://agupubs.onlinelibrary.wiley.com/doi/pdf/10.

Langergraber, G. (2008). Modeling of processes in subsurface flow constructed wetlands: A reviewall rights reserved. no part of this periodical may be re-755 produced or transmitted in any form or by any means, electronic or mechanical, including photocopying, recording, or any information storage and retrieval system, without permission in writing from the publisher. Vadose Zone Journal, 7, 830. URL: http://dx.doi.org/10.2136/vzj2007. 0054 doi $10.2136 / \mathrm{vzj} 2007.0054$
Langergraber, G. (2011). Numerical modelling: a tool for better constructed wetland design? Water Science and Technology, 64, 14-21. URL: http://wst.iwaponline. com/content/64/1/14 doi 10.2166/wst.2011.520 arXiv:http://wst.iwaponline.com/content/64/1/14.full.pdf

Maier, U., DeBiase, C., Baeder-Bederski, O., \& Bayer, P. (2009). Calibration of hydraulic parameters for large-scale vertical flow constructed wetlands. Journal of Hydrology, 369, 260 - 273. URL: http://www . sciencedirect.com/science/article/pii/S0022169409001139 doi https://doi.org/10.1016/j.jhydrol.2009.02.032 Transfer of pollutants in soils, sediments and water systems: From small to large scale (AquaTerra)

Moezzibadi, M., Charpentier, I., Wanko, A., \& Mosé, R. (2017). Sensitivity of groundwater flow with respect to the drain-aquifer leakage coefficient. Journal of Hydroinformatics, . doi 10.2166/hydro.2017.026

Moriasi, D., Arnold, J., Van Liew, M., Bingner, R., Harmel, R., \& Veith, T. (2007). Model evaluation guidelines for systematic quantification of accuracy in watershed simulations. Trans. of the American Society of Agricultural and Biological Engineers, Special Issue, 50.

Moriasi, D., Gitau, M., Pai, N., \& Daggupati, P. (2015). Hydrologic and water quality models: Performance measures and criteria. Trans. of the American Society of Agricultural and Biological Engineers, Special Issue, . URL:

http://handle.nal.usda.gov/10113/62083 doi 10.13031/trans. 58.10709

Morvannou, A., Forquet, N., Vanclooster, M., \& Molle, P. (2013). Characterizing hydraulic properties of filter material of a vertical flow constructed wetland. Ecological Engineering, 60, p. 325 - p. 335. URL: https://hal .archives-ouvertes.fr/hal-00926091 doi 10 . 1016/j.ecoleng.2013.06.042

Mualem, Y. (1976). A new model for predicting the hydraulic conductivity of unsaturated porous media. Water Resources Research, 12, 513522. URL: http://dx.doi.org/10.1029/WR012i003p00513 doi 10 . 1029/WR012i003p00513

Mualem, Y. (1984). A modified dependent-domain theory of hysteresis. Soil Science, 137, 283-291.

Naumann, U. (2011). The Art of Differentiating Computer Programs. Society for Industrial and Applied Mathematics. URL: http://epubs.siam.org/doi/abs/10.1137/1.9781611972078 doi $10.1137 / 1.9781611972078$

Nimmo, J. R. (2005). Unsaturated zone flow processes. In M. G. Anderson, \& J. Bear (Eds.), Encyclopedia of Hydrological Sciences chapter 150. (pp. 2299-2322). American Cancer Society.

Schmitt, N., Wanko, A., Laurent, J., Bois, P., Molle, P., \& Mosé, R. (2015). Constructed wetlands treating stormwater from separate sewer networks in a residential strasbourg urban catchment area: Micropollutant removal and fate. Journal of Environmental Chemical Engineering, 3, 2816 - 2824. URL: http://www. sciencedirect.com/science/article/pii/S2213343715300099 doi http://dx.doi.org/10.1016/j.jece.2015.10.008

Simunek, J., Sejna, M., Saito, H., \& van Genuchten, M. (2009). The HYDRUS$1 D$ software package for simulating the one-dimensional movement of water, heat and multiple-solutes in variably-saturated media.. University of California Riverside. URL: https ://www.pc-progress.com/Downloads/ Pgm_hydrus1D/HYDRUS1D-4.08.pdf

Tack, F., De Pauw, N., Du Laing, G., \& Rousseau, D. (2007). Contaminants in natural and constructed wetlands: Pollutant dynamics and control. Science of The Total Environment, 380, 1 - 2. URL: http://www. sciencedirect.com/science/article/pii/S0048969707002793 doi http://dx.doi.org/10.1016/j.scitotenv.2007.02.018 Contaminants in Natural and Constructed Wetlands: Pollutant Dynamics and Control.

Tang, X., Eke, P., Scholz, M., \& Huang, S. (2009). Processes impacting on benzene removal in vertical-flow constructed wetlands. WRBCib3eidorpo0 1/06ilnology, 100, 227 - 234. URL: http://www . sciencedirect.com/science/article/pii/S0960852408004872 doi http://dx.doi.org/10.1016/j.biortech.2008.05.038

Van Dam, J., \& Feddes, R. (2000). Numerical simulation of infiltration, evaporation and shallow groundwater levels with the richards equation. Journal of Hydrology, 233, 72 - 85. URL: http://www . sciencedirect.com/science/article/pii/S0022169400002274 doi http://dx.doi.org/10.1016/S0022-1694(00)00227-4 
Vymazal, J., \& Kropfelova, L. (2008). Wastewater Treatment in Constructed Wetlands with Horizontal Sub-Surface Flow. (1st ed.). Springer Netherlands. doi 10.1007/978-1-4020-8580-2

Walaszek, M., Bois, P., Laurent, J., Lenormand, E., \& Wanko, A. 765 (2018). Urban stormwater treatment by a constructed wetland: Seasonality impacts on hydraulic efficiency, physico-chemical behavior and heavy metal occurrence. Science of The Total Environment, 637 638, 443 - 454. URL: http://www.sciencedirect.com/science/

II article/pii/S0048969718315031 doi https://doi.org/10.1016/

770 j.scitotenv.2018.04.325

Wanko, A., Tapia, G., \& Mosé, R. (2015). Contribution to numerical modeling of water flow in variably saturated, heterogeneous porous media. Revue des sciences de l'eau, 28, 179-197.

Wanko, A., Tapia, G., Mosé, R., \& Gregoire, C. (2009). Ad775 sorption distribution impact on preferential transport within horizontal flow constructed wetland (hfcw). Ecological Modelling, 220, 3342 - 3352. URL: http://www.sciencedirect.com/science/

1] article/pii/S0304380009005730 doi https://doi.org/10.1016/ j.ecolmodel.2009.08.015

780 Younes, A., Mose, R., Ackerer, P., \& Chavent, G. (1999). A new formulation of the mixed finite element method for solving elliptic and parabolic pde with triangular elements. Journal of Computational Physics,

149, 148 - 167. URL: http://www.sciencedirect.com/science/

article/pii/S0021999198961502 doi https://doi.org/10.1006/

785 jcph.1998.6150

Zgheib, S., Moilleron, R., \& Chebbo, G. (2012). Priority pollutants in urban stormwater: Part 1 - case of separate storm sewers. Water Research, 46, 6683 - 6692. URL: http://www.sciencedirect.com/science/

article/pii/S0043135411007846 doi https://doi.org/10.1016/ j.watres.2011.12.012 Special Issue on Stormwater in urban areas. 